DOI: $10.22616 /$ REEP.2020.022

\title{
How to Measure Adolescents' Mathematical Competence
}

\author{
Aleksandrs Vorobjovs Mg.ed. \\ University of Latvia, Latvia \\ aleksandrs.vorobjovs@gmail.com
}

\begin{abstract}
Most education systems worldwide working to create or bring to life competencies-based education. There are a lot of debates on how to define competence itself, but there is some consensus on this question. Mostly, competences are understood as a combination of knowledge, skills and attitudes, nevertheless a lot of quite different interpretations of these key words exist on scientific and political level. Speaking of specific competencies, as especially mathematical competence, approaches differ significantly: if one respected group of authors offer a definition, where mathematical competence is a list of specific abilities, another also much citated source views mathematical competence as some sort of arithmetic mean or score of how many tasks pupil could handle. Therefore, the first aim of this study was to explore both concept of mathematical competence and adolescent characteristics in order to synthesize them. Changes in focus of education and methodology cause need of reviewing pupil evaluating process. Most publications on this topic mention formative assessment as if this form of evaluation was something new. What really is still unclear is how to measure complex competencebased knowledge, skills and attitudes. So, the second aim of this study is to provide a research-based approach on measuring adolescents' mathematical competence. The study was held as a theoretical comparison of the most popular and citated definitions of mathematical competence in order to find a suitable set of components to measure adolescents' mathematical competence.
\end{abstract}

Keywords: mathematical competence, levels of competence, performance level, school education.

\section{Introduction}

In studies published in Europe (Laursen, 2010; Niss, Højgaard, 2019; Turner, 2010), there are many different, sometimes contradictory interpretations of mathematical competence (in some sources mathematical competences or mathematical literacy). The most common explanation is interpreting mathematical competence as a list of specific skills, abilities and behaviours, which makes it easier to measure mathematical competence, since the definition itself gives some valid evaluation criteria (Laursen, 2010; Lee, 2016). Meanwhile, other authors define mathematical competence as the ability to use knowledge and skills in work and learning situations, as well professional and personal development (The Council of..., 2018).

Five main explanations of mathematical competence have been compiled in order to identify the most frequently mentioned components.

1. Author of "Teaching of Mathematical Modelling and Applications" Mogen Niss from Roskilde University, Denmark explains mathematical competence as the ability to understand, judge, do, and use mathematics in a variety of intra- and extra-mathematical contexts and situations in which mathematics plays or could play a role. Prerequisites for mathematical competence are lots of factual knowledge and technical skills (Niss, Højgaard, 2019).

2. Another Danish mathematician Kjeld Bagger Laursen from University of Copenhagen, cooperating with Institute of Mathematical Sciences, Centre for Science Education Knowledge, listed five abilities that determine mathematical competence: mathematical thinking, problem handling, modelling, reasoning and ability to deal with mathematical language and tools which includes representation, symbol and formalism, communication, aids and tools (Laursen, 2010).

3. Ross Turner from Australian Council for Educational Research (ACER) lists six mathematical competencies: communication, mathematising, representation, reasoning and argument, strategic thinking, using symbolic, formal and technical language and operations (Turner, 2010).

4. The Organisation for Economic Co-operation and Development (OECD) define mathematical literacy for its highly respected and frequently quoted Program for International Student 
Assessment (PISA) as individual's capacity to identify and understand the role that mathematics plays in the world, to make well-founded judgements and to use and engage with mathematics in ways that meet the needs of that individual's life as a constructive, concerned and reflective citizen (OECD, 2003). Since PISA test was first performed in 2000 and then repeated every three years, the definition of mathematical competence has remained almost the same.

5. European Parliament in its 2018 recommendations reaffirmed mathematical competence as one of eight key competences for life learning. EP offers definition, where mathematical competence is the ability to develop and apply mathematical thinking and insight in order to solve a range of problems in everyday situations. Mathematical competence involves, to different degrees, the ability and willingness to use mathematical modes of thought and presentation (formulas, models, constructs, graphs, charts). Building on a sound mastery of numeracy, the emphasis is on process and activity, as well as knowledge (The Council of..., 2018).

The three most frequently cited definitions of mathematical competence were formulated by R. Turner (2010), K.B. Laursen (2010), M. Niss and T. Højgaard (2019). Although these definitions have many similarities, each definition also has at least one specific aspect. The common and different contents of these definitions are shown in the Figure 1.

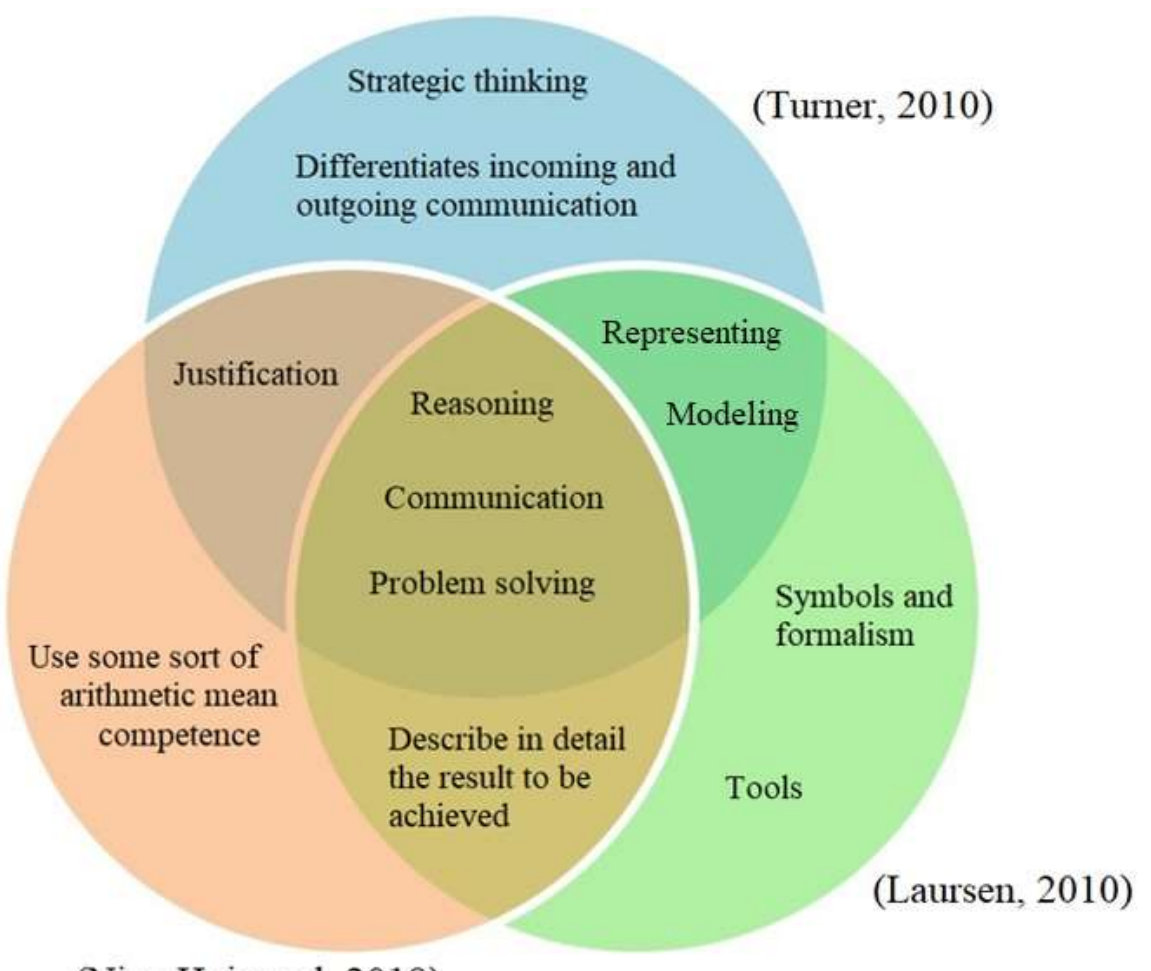

(Niss, Højgaard, 2019)

Figure 1. Comparison of three main definitions of mathematical competence.

Summarizing these five explanations of mathematical competence, it can be concluded that all five definitions refer to some form of communication, four definitions - to problem solving, three - to reasoning, two definitions to modelling, and one definition to the pupils' personality traits (Table 1). Extending list of definitions from five to eight, gives a quite similar result: all eight definitions include communication, six definitions to reasoning and problem solving, three definitions to modelling, and one definition to the adolescent personality traits.

These five components have been supplemented by mathematical intuition and self-reflection as they have been mentioned over the centuries as being critical to the development of mathematical competence (Casselman, 1897; Kahneman, 2011; Kolmogorov, 1988; Poincare, 1905).

In a survey held between 2016 and 2018 students themselves described mathematical competence as the use of symbol language, mathematical representation, problem solving, opinion formation and others. More than $10 \%$ of students who took part in this survey considered that they are unable to solve problems 
and have not developed mathematical thinking (Zeidmane, Rubina, 2018). This shows that students have a lower self-esteem than their reported scores at age 15 , when only approximately $5 \%$ of Latvian $8^{\text {th }}$ and $9^{\text {th }}$ graders are unable to solve mathematical problem with a familiar context that contains relevant information that requires to perform routine actions (OECD, 2018). Pupils identify mathematics as subject that helps them to improve how they think and how they solve problems, it improves technical thinking and overtaking obstacles and gives solid background (Vintere, Cernajeva, 2019).

Table 1

Components of mathematical competence in main definitions of mathematical competence

\begin{tabular}{lccccc}
\hline $\begin{array}{c}\text { Components of } \\
\text { mathematical } \\
\text { competence }\end{array}$ & OECD & $\begin{array}{c}\text { The Council of } \\
\text { the European } \\
\text { Union }\end{array}$ & Niss & Laursen & Turner \\
\hline Communication & $\mathrm{x}$ & $\mathrm{x}$ & $\mathrm{x}$ & $\mathrm{x}$ & $\mathrm{x}$ \\
Reasoning & $\mathrm{x}$ & $\mathrm{x}$ & $\mathrm{x}$ & $\mathrm{x}$ \\
Problem solving & & $\mathrm{x}$ & $\mathrm{x}$ & $\mathrm{x}$ \\
Modelling & & $\mathrm{x}$ & $\mathrm{x}$ & $\mathrm{x}$ \\
Personality traits & & & & \\
\hline
\end{tabular}

Sources: (OECD, 2003; The Council of..., 2018; Niss, 2011; Laursen, 2010; Turner, 2011).

Adolescents in the context of this article are students at age of 15 . There are three main reasons why this age has been chosen. First, at this age students graduate from compulsory middle school, which is quite similar in its curriculum around the world, which allows to objectively compare the results of 15-yearolds in different regions. Second, at this age students make their decision on whether to continue education in high school. On average every tenth student in Europe does not continue formal education after middle school, therefore it is very important to give a reliable feedback on what competence have they accumulated before leaving school. Finally, this is the age when most adolescents are becoming aware of their potential engineering or humanitarian education pathways and careers, so it is particularly important at this age to investigate whether teens have sufficient mathematical competence to choose a mathematical - technological career path (Croll, Attwood, Fuller, 2011).

There is a major contradiction in this age group: adolescents tend to imitate adult behaviour norms but are not ready to take responsibility. Adolescent does not want to be perceived as a child, so subconsciously will develop an attitude towards an adult who, with advice, criticism, criticism and ridicule, does not allow the teenager to truly feel an adult. As a result, adults are no longer teenagers. The new authority becomes the peer, or the teenager has no authority at all. At this stage, there is an intense awareness of one's own identity when evaluating other people's standards of behaviour, morals and ethics (Levesque, 2018).

Several researches show that today's adolescents tend to emphasize they uniqueness by using IT and digital-related terms and slang that is usually unfamiliar for representatives of older generations. Although, adolescents' often overestimate their knowledge about computer and online tools, this is why researchers from different countries are unanimous that tablet PCs, mobile phones, interactive boards, on-line tests and many other so-called new technologies are just modern "digital toys" with no or very little impact on pupil results (Andersone, 2017).

Relevant information about today's teenagers can be found in intergenerational research. W. Strauss and $\mathrm{N}$. Howe are known in generational research for proposing the generation $\mathrm{Y}$ to be called millennials. By the age range proposed by these authors, by the year 2025, 15 -year-olds will be part of the $\mathrm{Z}$ generation, or, in the figurative terms of W. Strauss and N. Howe the "home-sitters generation", also known as digital natives (Figure 2). According to W. Strauss and N. Howe Generation Theory, Z generation teenagers will be replaced by the alpha $(\alpha)$ generation or "digital babies" for the next 15 years (Howe, Strauss, 2008).

Based on the analysis of understanding of mathematical competence and adolescent characteristics, each component of mathematical competence was described in detail in order to classify adolescent performance into four levels: excellent, good, weak and none. These levels can be used as criteria for measuring adolescents' mathematical competence. 
The aim of the study is to provide a research-based approach on measuring adolescents' mathematical competence, exploring both concept of mathematical competence and adolescent characteristics in order to synthesize them.

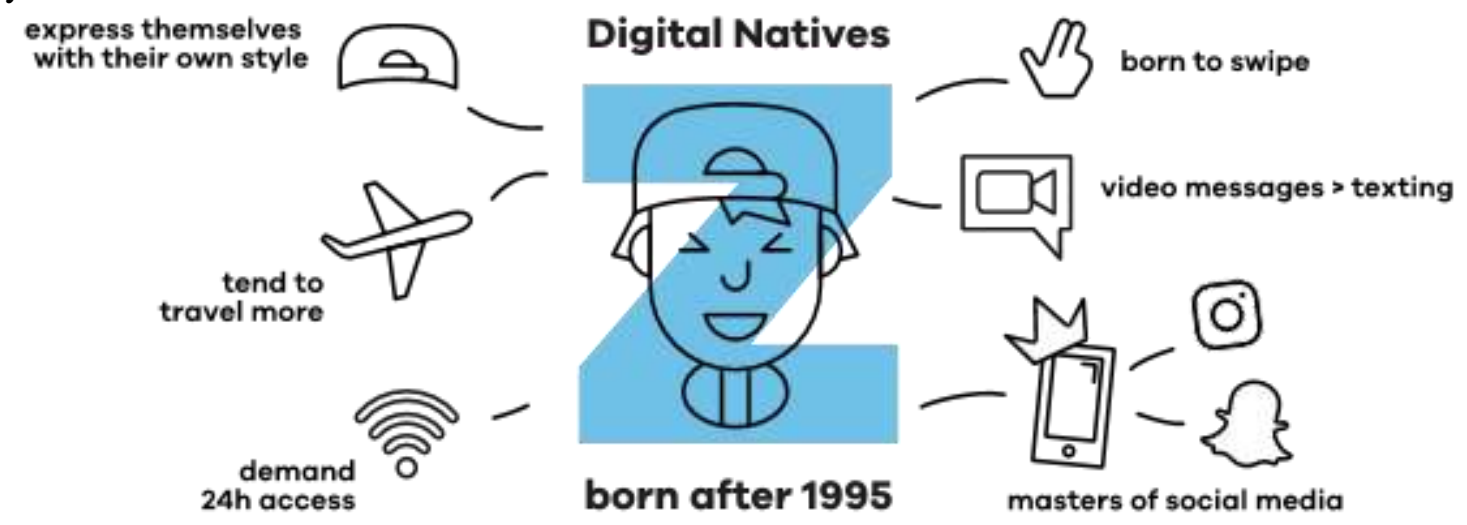

Figure 2. Characteristics of generation Z (Von Jörg, 2017).

\section{Methodology}

In order to identify appropriate measure methods to evaluate adolescents' mathematical competence, researches on structure, formation and indication of mathematical competence as well as adolescents' characteristics have been studied. Research is based on analyses of five most influential approaches to define mathematical competence (The Council of..., 2018; Laursen, 2010; Niss, Højgaard, 2019; OECD, 2003; Turner, 2010).

The question of the study is how to measure adolescents' mathematical competence. The study carries out qualitative content analysis. Based on this analysis, seven components of mathematical competence were selected for which four levels of achievement were described.

\section{Results and Discussion}

Considering theoretical investigation of adolescents' mathematical competence, it is possible to determine seven components of mathematical competence (Figure 3). Each component has been described using achievement level descriptions. These four levels are pronounced, good, poor and no or zero level. Descriptions of levels build from the lowest to the highest, emphasizing additional knowledge, skills and attitudes adolescent should show to get a higher level.

For example, personal traits as useful for acquiring mathematical competence has been described in general by Czech researchers based on the interpretation of the European Commission Frame of key competencies for lifelong learning. In this research mathematical competence was formulated from the learner's perspective: I have the ability to develop and apply mathematical thinking to solve problems in various everyday situations; I have the ability and willingness to use these mathematical ways of thinking (logical and spatial thinking) and presentation: formulas, models, figures, charts and diagrams (Smékalová, Němejc, 2016).

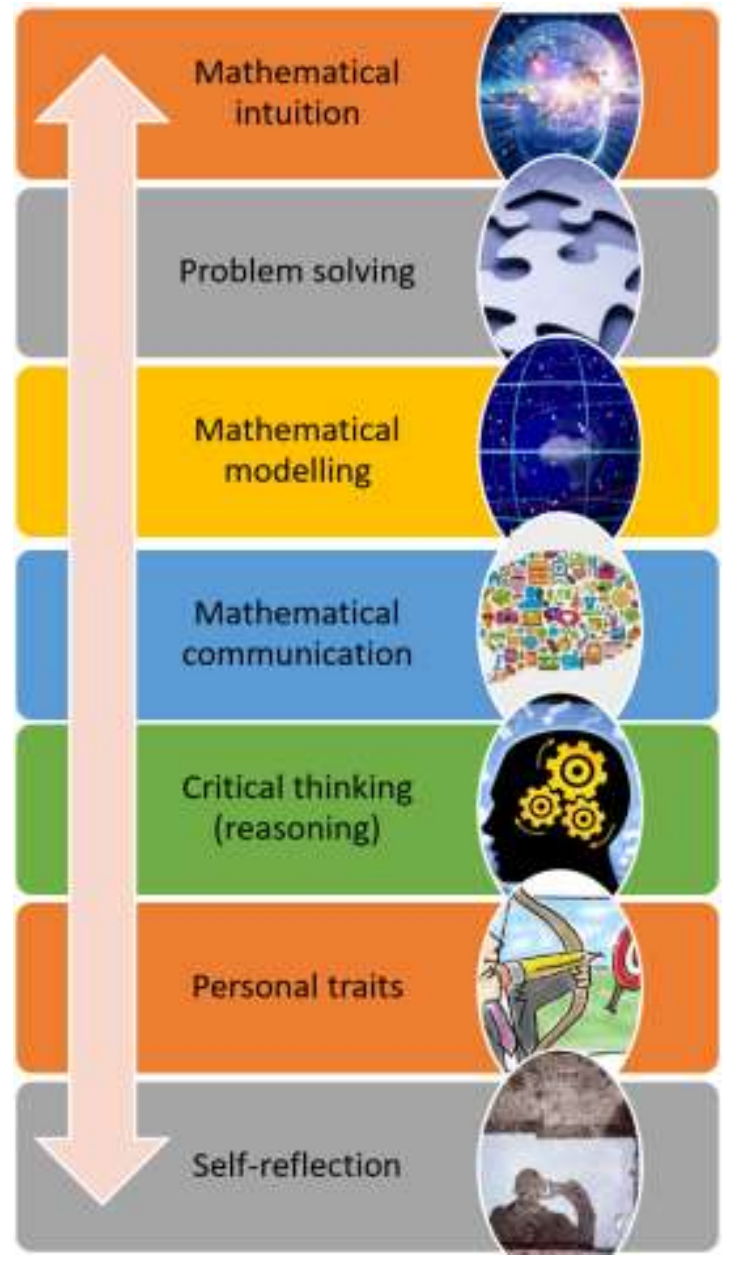

Figure 3. Components of mathematical competence. 
In this research each component of mathematical competence is not only described from learner's perspective, indicating specific skills, skills, knowledge and attitudes, but also these criteria are divided into four levels for easy use as a tool for measuring mathematical competence.

Zero level for personal traits indicates that in a given situation and with some specific task does not know how to set long-term goals or does not follow them if someone else helps to set these goals and gives up facing a new kind of problem. This does not describe action of an adolescent, neither his or her personality in every learning situation, so for a different task pupil could achieve poor, good or even pronounced level. To get from zero to poor level pupil should show a small effort when faced a new type of problem situation, even if it does not lead to a solution of this problem. To certify for the third good level pupil is supposed to do a lot more: act independently, purposefully, effectively and responsibly, most likely to be persistent in learning, actively follow what is happening and reach the goals even despite the difficulties and obstacles. As for the pronounced level, in some ways it can be viewed as an expert level. As mentioned before, this level includes all productive features of the lower levels and has some extra indicators. More specifically for personal traits, these additional criteria are not only persistence in reaching for the goal the teacher has set, but also initiative in learning: proposing ideas, participating in their realization, curiosity seen as developing new, innovative solutions, translating these ideas into practice. Pupils on an expert level of personal traits crucial for learning mathematics do their work thoroughly, diligently, in the highest quality and productive manner.

Other six components of mathematical competences are described in a similar manner and will be discussed along with the first data on adolescents' mathematical competence levels in the next publications.

\section{Conclusions}

Since mathematical competence in a highly complex construct, as shown by analysis of previous researches on this topic, to measure it appropriately requires science based, accurate and sensitive measuring tool, that is at the same time convenient and intuitive in use. It appears that grading or testing is not valid for this purpose. To consider the characteristics of adolescents this measurement must reflect specific traits of target audience such as psychological instability, disorder, rapid change of mood and priorities. All of them and many other could be mistakenly considered to be a lack of mathematical competence, which means criteria should be very precise, unambiguous and objective. Considering theoretical investigation of adolescents' mathematical competence, seven components of mathematical competence have been determined. They are mathematical intuition, problem solving, mathematical modelling, mathematical communication, critical thinking, personal traits and self-reflection. An example of levels of performance for personal traits is given in this publication.

Measuring adolescents' mathematical competence their characteristics also should be considered. Adolescents tend to have a critical view of the world, which leads to a deeper understanding of problems and concepts, also allowing to find more flaws that are not obvious. Since adolescents appreciate novelty, innovation and opportunity to share ideas, mathematics education should encourage adolescents to discover new ideas, relationships, look for applications, solve problems and explain them to others. Based on the above, adolescents' mathematical competence has been defined as a set of skills and attitudes that allow them to understand and solve a variety of problems, use generalized models, critically evaluate and justify a result, use mathematically correct language.

\section{Bibliography}

1. Andersone R. (2017). The Learning Environment in Today's School in the Context of Content Reform of Curriculum. In V. Dislere (Ed.), The Proceedings of the International Scientific Conference Rural Environment. Education. Personality (REEP), 10. Jelgava: LLU, 17-22. Retrieved from https://llufb.llu.lv/conference/REEP/2017/Latvia-Univ-Agricult-REEP2017_proceedings-17-22.pdf

2. Casselman B. (1897). Archimedes' quadrature of the parabola. Cambridge University Press.

3. Croll P., Attwood G., Fuller C. (2011). Children's Lives, Children's Futures: A Study of Children Starting Secondary School. Continuum Studies in Educational Research, Continuum. 
4. Howe N., Strauss W. (2008). Millennials Go to College: Strategies for a New Generation on Campus ( $2^{\text {nd }}$ ed.). Great Falls: LifeCourse Associates.

5. Kahneman D. (2011). Thinking, Fast and Slow. London, Panguin Books.

6. Kolmogorov A. (1988). Matematika - nauka i professija [Mathematics - Science and Profession]. Bibliotechka Kvanta, Moscow. (in Russian)

7. Laursen K.B. (2010). Competence Driven Teaching of Mathematics. Copenhagen: Institute of Mathematical Sciences, Centre for Science Education, University of Copenhagen.

8. Lee K. (2016). Mathematical Competence, Teaching, and Learning. Reflections on 'Challenges in Mathematical Cognition' by Alcock et al. (2016). Journal of Numerical Cognition, 2(1), 48-52. doi: 10.5964/jnc.v2i1.25

9. Levesque R.J.R. (2018). Encyclopedia of Adolescence. Springer-Verlag New York.

10. Niss M., Højgaard T. (2019). Mathematical competencies revisited. Educational Studies in Mathematics, 102(1), 9-28. doi: 10.1007/s10649-019-09903-9

11. OECD. (2003). The PISA 2003 Assessment Framework - Mathematics, Reading, Science and Problem Solving Knowledge and Skills. Retrieved from http://www.oecd.org/education/school/programmeforinternationalstudentassessmentpisa/33694881.pdf

12. OECD. (2018). PISA 2015 Results in Focus. Paris: OECD Publishing. Retrieved from https://www.oecd.org/pisa/pisa-2015-results-in-focus.pdf

13. Poincare H. (1905). On the nature of mathematical Reasoning. Chapter 1 in Science and Hypothesis. London: Walter Scott Publishing. Retrieved from https://archive.org/download/scienceandhypoth00poinuoft/scienceandhypoth00poinuoft.pdf

14. Smékalová L., Němejc K. (2016). Transferable Competencies of Graduates of Vocational Education: a Retrospective Survey 2007-2014. In V. Dislere (Ed.), The Proceedings of the International Scientific Conference Rural Environment. Education. Personality (REEP), 9. Jelgava: LLU, 106-113. Retrieved from https://llufb.llu.lv/conference/REEP/2016/Latvia-UnivAgricult-REEP-2016proceed2255-808X-106-113.pdf

15. Council Recommendation on Key Competences for Lifelong Learning. (2018). European Commission. Official Journal of the European Union, 189(1). Retrieved from https://eurlex.europa.eu/legal-content/EN/TXT/PDF/?uri=CELEX:32018H0604(01)\&from=EN

16. Turner R. (2010). Exploring Mathematical Competencies. Research Developments, 24. Retrieved from https://research.acer.edu.au/resdev/vol24/iss24/5/

17. Vintere A., Cernajeva S. (2019). A Case of Competence Building - International Student Scientific Mathematics Olympiad. In V. Dislere (Ed.), The Proceedings of the International Scientific Conference Rural Environment. Education. Personality (REEP), 12. Jelgava: Latvia University of Life Sciences and Technologies, 196-202. doi: 10.22616/REEP.2019.025

18. Von Jörg M. (2017). Introducing: Generation Z. En Garde. Retrieved from https://www.engarde.net/introducing-generation-z/

19. Zeidmane A., Rubina T. (2018). The Contribution of Mathematics to the Engineering Education in the Students' Assessment. In V. Dislere (Ed.), The Proceedings of the International Scientific Conference Rural Environment. Education. Personality (REEP), 11. Jelgava: Latvia University of Life Sciences and Technologies, 243-250. doi: 10.22616/REEP.2018.030 